\title{
Analisa Perawatan Diesel Engine Generator (DEG) Tunu South Production Platform Pertamina Hulu Mahakam
}

\author{
Abdul Zain ${ }^{1 *}$ dan Wildan Alif Imam Putra ${ }^{2}$ \\ ${ }^{1,2}$ Program Studi Teknik Elektro, Sekolah Tinggi Teknologi Bontang, Bontang, Indonesia \\ *email: jainbtg2013@gmail.com
}

\begin{abstract}
Routinely, oil and gas activity at PT Pertamina Hulu Mahakam has been supplying electric power by Diesel Engine Generator (DEG). Writer takes this research object because Diesel Engine Generator is one of the critical asset with intention of understand preventive maintenance procedural steps, frequent faults occur during electrical generation system. Writer takes this analysis based on operational history from least one year occured fault auxiliary system frequently. Such as current transformer and magnetic pick-up which involving a process shutdown and loss electrical power causes less contribution on Tunu South Production Platform. And other reason cause unplanned shutdown were during maintenance on 6 monthly nor Yearly didn't checking on auxiliary system, The procedure wasn't update causes unplanned shutdown possibility in the further.
\end{abstract}

Keywords: current transformer; DEG; magnetic pick-up; maintenance

\begin{abstract}
Abstrak: Dalam kegiatan produksi PT Pertamina Hulu Mahakam sumber listrik disupply oleh Diesel Engine Generator (DEG), peneliti memilih obyek penelitian sistem DEG karena merupakan salah satu aset kritis, dengan tujuan untuk mengetahui tata cara pemeliharaan dan kegagalan fungsi yang sering terjadi dalam pembangkitan energi listrik. Peneliti memilih untuk mengambil analisa pemeliharaan DEG dan mendapat kesimpulan dalam riwayat operasional dalam satu tahun terakhir penyebab terjadi kegagalan (failure) fungsi sistem auxiliary DEG seperti pada komponen current transformer dan magnetic pick-up yang mengakibatkan shutdown dan loss power pada platform yang berdampak pada kurangnya kontribusi Platform Tunu South. Dan penyebab lain terjadinya unplanned shutdown karena saat dilakukan perawatan baik 6 bulanan atau pun 1 tahun tidak ada dilakukan pengecekan pada system auxiliary tersebut, sehingga kurang update prosedur pemeliharaan memungkinkan terjadinya unplanned shutdown selanjutnya.
\end{abstract}

Kata kunci : current transformer; DEG; magnetic pick-up; perawatan

\section{PENDAHULUAN}

Tunu South Production Platform merupakan salah satu instalasi produksi yang dimiliki PT. Pertamina Hulu Mahakam dan Diesel Engine Generator (DEG) merupakan pembangkit utama energi listrik di Tunu South Production Platform. Terdapat dua DEG Leroy Somer tipe LSA 44.2L12 dengan kapasitas $50 \mathrm{KVA}$ atau sekitar $40 \mathrm{KW}$ keluaran tegangan $380 \mathrm{~V}$ dan arus $72 \mathrm{~A}$, yang mana kedua DEG tersebut berkerja secara bergantian setiap 10 harinya untuk kebutuhan energi listrik di platform [1]. Karena pentingnya fungsi generator sebagai power generation yang tidak boleh terganggu availability dan reliability nya, maka cara perawatan yang dilakukan harus sesuai standar perusahaan agar mendapat hasil yang efektif dan maksimal guna menghindari terjadinya unplanned shutdown, atau gangguan yang terjadi pada supply kellistrikan di platform [2][3]. Jika sebuah peralatan tersebut mengalami kerusakan maka akan menghambat proses produksi tenaga listrik. Untuk itu diperlukan perawatan secara berkala dan terus menerus agar dapat mengindari kerusakan yang ditimbulkan akibat proses produksi yang dilakukan terus menerus [4][5].

Namun permasalahan utama yang sering dihadapi adalah terjadinya unplanned shutdown yang disebabkan oleh gangguan internal yaitu gangguan yang disebabkan kerusakan pada internal parts generator itu sendiri atau gangguan external yaitu gangguan yang disebabkan oleh beban yang di supply oleh generator. Kejadian unplanned shutdown itu pernah terjadi ketika generator mengalami gangguan under voltage, yaitu salah satu tegangan output dari generator tidak mencapai angka 400 
VAC karena salah satu current transformer atau trafo arus mengalami kerusakan. Maka dari itu salah satu cara agar kejadian unplanned shutdown tidak berulang kembali dan mengganggu sistem operasional perusahaan dilakukan perawatan atau maintenance secara periodik yaitu dengan durasi waktu 2000 Jam atau 6 Bulan dan 4000 Jam atau 1 Tahun.

\section{METODE PENELITIAN}

Dalam penulisan tugas akhir ini tidak lepas dari proses pengambilan data dilapangan PT. Pertamina Hulu Mahakam sebagai landasan pembuatan tugas akhir, maka ada beberapa hal dalam teknik pengumpulan data yang dilakukan, antara lain:

1. Studi Pustaka, Untuk mencari data autentik mengenai teori tentang diesel engine generator pada lapangan minyak dan gas.

2. Survei Lapangan, Untuk memperoleh data-data lapangan yang dibutuhkan, prinsip dan deskripsi kerja Diesel Engine Generator serta melakukan pengukuran di lapangan minyak dan gas.

3. Konsultasi dengan Pembimbing, Untuk memperoleh saran-saran yang diperlukan dalam penulisan tugas akhir ini supaya lebih berkualitas.

4. Penulisan Laporan, Setelah mendapatkan semua referensi, data, dan saran yang mendukung isi laporan, maka laporan tugas akhir dapat ditulis sesuai tujuan dan pembahasan.

Tabel 1. Kejadian Unplanned Shutdown Sebelum Perawatan

\begin{tabular}{|c|c|}
\hline Tanggal Kejadian & Jenis Gangguan \\
\hline 18/April/2019 & Generator Under Voltage \\
\hline $16 /$ May/2019 & Coupling Fault Alarm \\
\hline
\end{tabular}

\section{HASIL DAN PEMBAHASAN}

Untuk kegiatan perawatan 6 bulanan dapat dijabarkan sebagai berikut :

Tabel 2. Perawatan Frame Generator

\begin{tabular}{|l|l|}
\hline \multicolumn{2}{|c|}{ Masalah Sebelum Pemeliharaan } \\
\hline $\begin{array}{l}\text { Rangka ditemukan dalam keaadaan kotor dan berdebu, baik diluar maupun dalam generator } \\
\text { package. Rangka baut ditemukan beberapa kendur. }\end{array}$ \\
\hline \multicolumn{2}{|c|}{ Cara Pemeliharaan } \\
\hline $\begin{array}{l}\text { frame dibersihkan di seluruh area yang terlihat kotor dan penuh dengan debu - debu halus } \\
\text { hingga mengkilat. Kedua, mengencangkan baut - baut yang menyokong generator frame } \\
\text { menggunakan kunci pas yang sesuai dengan ukurannya. }\end{array}$ \\
\hline \multicolumn{1}{|c|}{ Setelah Dilakukan Perawatan } & \multicolumn{1}{c|}{ Analisa Setelah perawatan } \\
\hline $\begin{array}{l}\text { Rangka Generator baik dalam maupun luar } \\
\text { menjadi lebih bersih. Rangka baut generator } \\
\text { yang kendur menjadi kencang. }\end{array}$ & $\begin{array}{l}\text { Seharusmya ada improvement agar kotoran } \\
\text { juga tidak masuk ke dalam package diesel } \\
\text { generator dengan mengecek rubber seal di } \\
\text { setiap sudut yang bisa dibuka. Rangka baut } \\
\text { yang sudah kencang membuat generator } \\
\text { tertopang lebih kuat dan tahan terhadap } \\
\text { vibrasi yang disebabkan putaran mesin. Dan } \\
\text { seharusnya saat pengencangan memakai kunci } \\
\text { torsi sesuai rujukan manufaktur [6]. }\end{array}$ \\
\hline
\end{tabular}


208 Abdul Zain, Wildan Alif Imam Putra. Analisa Perawatan Diesel Engine Generator (DEG) Tunu South Production Platform Pertamina Hulu Mahakam

Tabel 3. Perawatan Motor Starter

Masalah Sebelum Pemeliharaan

Sambungan terminal kendur dan juga cukup berkarat antara motor starter dengan baterai sehingga tegangan hanya 11,4 VDC, sambungan antara baterai dan solenoid kendur sehingga tegangan terukur hanya 11,2 VDC.

Cara Pemeliharaan

Periksa koneksi elektrikal antara baterai starter, solenoid, dan starter motor terminal.

Pemeriksaan koneksi elektrikal ini dapat dibagi menjadi 3 bagian :

- Periksa tegangan baterai yang digunakan motor starter. Pastikan stabil pada 12 Volt DC. Jika baut longgar, kencangkan baut.

- Periksa tegangan dan polaritas antara baterai dengan solenoid. Pastikan nilai 12 V DC. Baut terminal yang meghubungkan kedua kabel jika terindikasi longgar, segera kencangkan.

\begin{tabular}{l|l|}
\hline \multicolumn{1}{|c|}{ Setelah Dilakukan Perawatan } & \multicolumn{1}{c|}{ Analisa Setelah perawatan } \\
\hline $\begin{array}{l}\text { Tegangan antara motor starter dengan baterai } \\
\text { 12,2 VDC setelah dilakukan pengencangan } \\
\text { dan pembersihan terminal ulang. }\end{array}$ & $\begin{array}{l}\text { Langkah perawatan sangat efektif sehingga } \\
\text { meningkatkan supply tegangan nominal yang } \\
\text { Tegangan solenoid dengan baterai mencapai } \\
\text { ditentukan yaitu 12 VDC dimana sebelumnya } \\
\text { 12,1 VDC setelah dilakukan pengencangan } \\
\text { tidak mencapai angka terebut yaitu 11,4 VDC } \\
\text { untuk motor dan 11,2 VDC untuk solenoid }\end{array}$ \\
& {$[7]$.}
\end{tabular}

Tabel 4. Perawatan Baterai

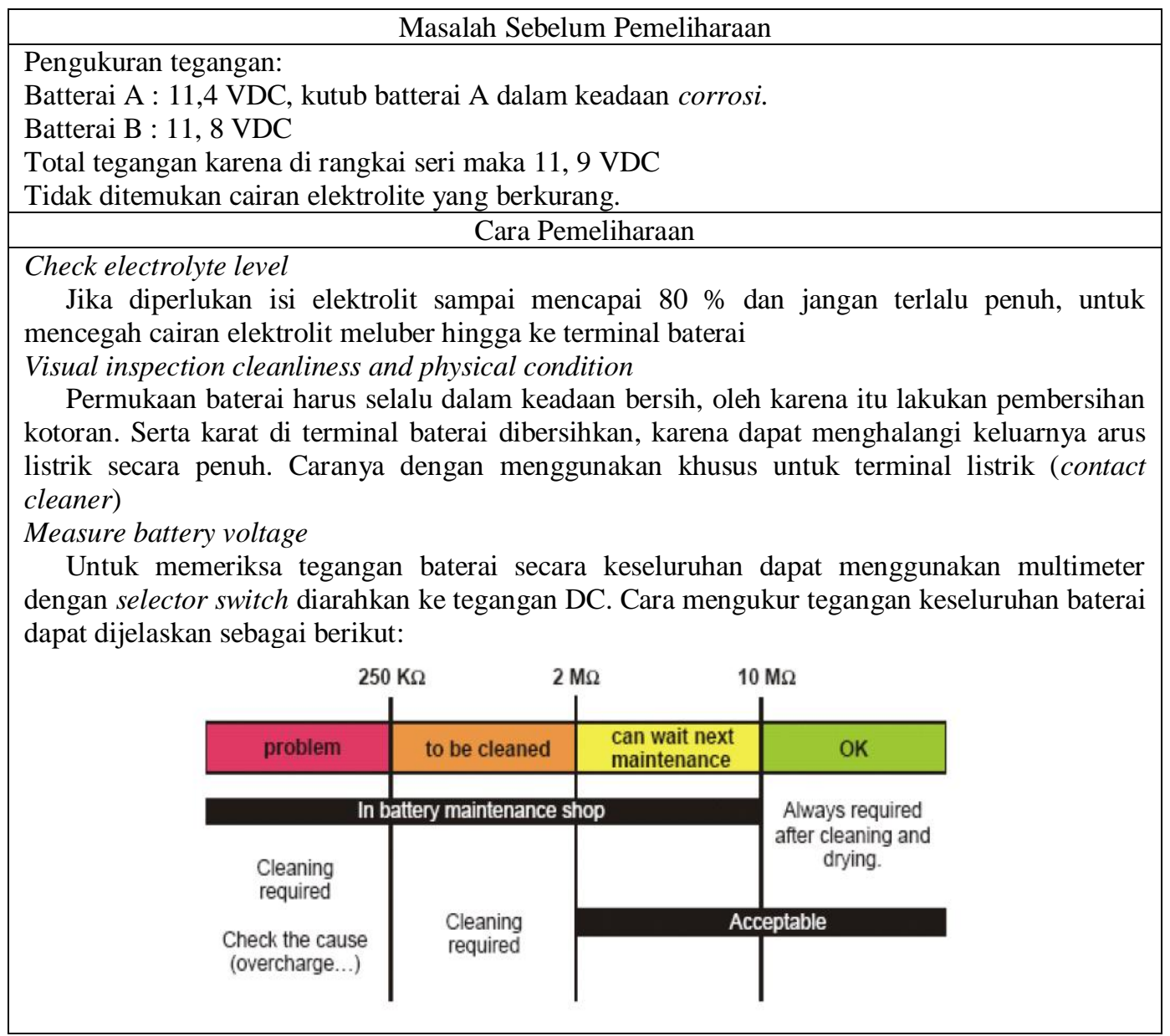




\begin{tabular}{|l|l|}
\hline \multicolumn{1}{|c|}{ Setelah Dilakukan Perawatan } & \multicolumn{1}{c|}{ Analisa Setelah perawatan } \\
\hline Kutub baterai A yang corrosi dibersihkan & Langkah perawatan yang dilakukan sudah cukup \\
lalu dilakukan pengukuran setiap cell & baik, concern utama yaitu corrosi juga di treatment \\
battery mendapat hasil yaitu & dengan baik, sehingga menjaga ouput voltage \\
Batterai A 11,9 VDC & batterai itu sendiri di nominal 12,4 VDC. Hanya \\
Batterai B 12,2 & saja masalah corrosive yang susah dihilangkan \\
Total tegangan 12,4 & karena memang kadar asam di cairan elektrolit \\
& cukup tinggi. Sebaiknya batterai diinstal dalam \\
& kotak panel dan diberi butiran silicagel untuk \\
& mengurangi intensitas karat agar perawatan lebih \\
& efektif [8]. \\
\hline
\end{tabular}

Tabel 5. Perawatan Winding Space Heater

\begin{tabular}{|l|l|}
\hline \multicolumn{2}{|c|}{ Masalah Sebelum Pemeliharaan } \\
\hline $\begin{array}{l}\text { Ditemukan output tegangan 180VAC karena beberapa terminal kendur dan winding yang } \\
\text { kotor dan temperatur mendekati ambient temperature yaitu 28'C }\end{array}$ \\
\hline \multicolumn{2}{|c|}{ Cara Pemeliharaan } \\
\hline \multicolumn{2}{|c|}{ Space heater adalah auxiliary generator yang berfungsi memanaskan stator winding } \\
ketika DEG dalam kondisi mati. Perawatannya dengan melakukan functional test, \\
membersihkan bagian konduktor heater dengan contact cleaner, pengencangan baut terminal \\
di koneksi. Cara pemeliharaannya dengan mengukur terminal yang ke local heater, jika \\
tegangan sekitar 220 Volt dipastikan heater dalam kondisi bagus.
\end{tabular}

Untuk kegiatan perawatan 1 tahunan dapat dijabarkan sebagai berikut :

Tabel 6. Perawatan Stator Winding

Masalah Sebelum Pemeliharaan

\begin{tabular}{l} 
Turunnya tahanan isolasi karena kotor dan tingkat kelembapan yang cukup tinggi, nilai yang \\
terukur Phase to Ground yaitu : \\
$\mathrm{R} / \mathrm{E} 26,5 \mathrm{M} \Omega$ \\
$\mathrm{S} / \mathrm{E} 25,3 \mathrm{M} \Omega$ \\
$\mathrm{T} / \mathrm{E} 26,9 \mathrm{M} \Omega$ \\
Lalu Phase to Phase: \\
$\mathrm{R} / \mathrm{S} 44,2 \mathrm{M} \Omega$ \\
$\mathrm{R} / \mathrm{T} 43,6 \mathrm{M} \Omega$ \\
$\mathrm{S} / \mathrm{T} 43,8 \mathrm{M} \Omega$ \\
\hline \\
\hline \\
Stator winding dirawat dengan mengukur tahanan isolasi menggunakan alat ukur mega ohm \\
meter atau sering disebut megger test. Parameter yang diukur terdiri dari dua macam, yaitu \\
antara fasa ke fasa dan fasa ke ground [7]. \\
\hline
\end{tabular}




$$
\begin{aligned}
& I R=(1000 \times \text { Vout }) \Omega+1 M \Omega \\
& I R=(1000 \times \text { Vout }) \Omega+1 M \Omega \\
& I R=(1000 \times 400 V) \Omega+1 M \Omega \\
& I R=0,4 M \Omega+1 M \Omega \\
& I R=1,4 M \Omega
\end{aligned}
$$

\begin{tabular}{|c|c|}
\hline \multicolumn{2}{|c|}{ Masalah Sebelum Pemeliharaan } \\
\hline \multicolumn{2}{|c|}{$\begin{array}{l}\text { Turunnya tahanan isolasi karena kotor dan tingkat kelembapan yang cukup tinggi, nilai yang } \\
\text { terukur yaitu Phase to Ground } \\
\text { Positif/E :1,022 } \mathrm{M} \Omega \\
\text { Negatif/E : } 1,020 \mathrm{M} \Omega \\
\text { Dan Positif to Negatif } 1,021 \mathrm{M} \Omega \text {. artinya winding dalam keadaan low insulation. }\end{array}$} \\
\hline \multicolumn{2}{|c|}{ Cara Pemeliharaan } \\
\hline \multirow{2}{*}{\multicolumn{2}{|c|}{$\begin{array}{l}\text { Pengukuran tahanan isolasi main field, exciter field dan exciter armature winding sama } \\
\text { dengan mengukur tahanan isolasi untuk kumparan lainnya. } \\
\text { Berdasarkan data nameplate dari lapangan, tegangan kerja semua kumparan rotor yaitu } 24 \\
\text { Volt DC. Maka minimal tahanan isolasi rumus : } \\
\qquad \begin{array}{l}I R=(1000 \times V o u t) \Omega+1 M \Omega \\
\qquad I R=(1000 \times 24 V) \Omega+1 M \Omega \\
\qquad I R=0,024 M \Omega+1 M \Omega\end{array} \\
\qquad \begin{array}{l}\text { Dengan hasil yang diperoleh dari perhitungan, diketahui bahwa kumparan rotor yang bagus } \\
\text { memiliki tahanan isolasi lebih dari } 1,024 \mathrm{M} \Omega\end{array}\end{array}$}} \\
\hline & \\
\hline Setelah Dilakukan Perawatan & Analisa Setelah perawatan \\
\hline $\begin{array}{l}\text { Dilakukan pembersihan di lilitan dan } \\
\text { terminal serta space heater yang } \\
\text { sudah bekerja maka tahanan isolasi } \\
\text { Positif/E }: 1,032 \mathrm{M} \Omega \\
\text { Negatif/E : } 1,029 \mathrm{M} \Omega \\
\text { Dan Positif to Negatif } 1,028 \mathrm{M} \Omega \text {. } \\
\text { artinya winding dalam keadaan tidak }\end{array}$ & $\begin{array}{l}\text { Cara pemeliharaan sudah efektif karena mampu } \\
\text { menaikkan nilai tahanan resistansi diatas standar yaitu } \\
1,024 \mathrm{M} \Omega \text { yang sebelumnya di bawah nilai tersebut } \\
\text { sekaligus mengurangi kerusakan lilitan rotor, namun } \\
\text { sama halnya dengan lilitan stator seharusnya } \\
\text { dilakukan continuity test resistance dan polarization } \\
\text { test. }\end{array}$ \\
\hline
\end{tabular}

Dari hasil perhitungan maka tahanan isolasi minimal yang diperbolehkan sesuai standar adalah 1,4 M $\Omega$ karena tegangan kerja 400VAC.

\begin{tabular}{|l|l|}
\hline \multicolumn{1}{|c|}{ Setelah Dilakukan Perawatan } & \multicolumn{1}{c|}{ Analisa Setelah perawatan } \\
\hline dengan dilakukan pengencangan, & Kenaikan nilai pengukuran tahanan isolasi \\
pembersihan dan meng-energized space & yang sangat signifikan namun harusnya \\
heater nilai tahanan isolasi menjadi: & ditambah metode continuity resistance test \\
R/E 37,5 M $\Omega$ & antar liitan untuk mengetahui apakah masih \\
$\mathrm{S} / \mathrm{E} \mathrm{33,8} \mathrm{M} \Omega$ & tersambung antar lilitan atau tidak. Dan juga \\
T/E 34,6 M, & harusnya dilakukan Polarization Index test \\
Lalu Phase to Phase: & untuk mengetahui kualitas lilitan terhadap \\
$\mathrm{R} / \mathrm{S} \mathrm{44,6} \mathrm{M} \Omega$ & lingkungan. \\
$\mathrm{R} / \mathrm{T} 47,4 \mathrm{M} \Omega$ & \\
$\mathrm{S} / \mathrm{T} 43,9 \mathrm{M} \Omega$ & \\
\hline
\end{tabular}

Tabel 7. Perawatan Rotor Winding 


\begin{tabular}{|c|c|}
\hline \multicolumn{2}{|l|}{ low insulation. } \\
\hline \multicolumn{2}{|c|}{ Tabel 8. Perawatan Rotating Diode } \\
\hline \multicolumn{2}{|c|}{ Masalah Sebelum Pemeliharaan } \\
\hline \multicolumn{2}{|c|}{$\begin{array}{l}\text { Ditemukan baut terminal kendur karena efek panas dari arus yang mengalir. Tegangan yang } \\
\text { diukur masih dalam batas normal yaitu : } \\
\text { Diode } A: 0,41 \\
\text { Diode } \mathrm{B}: 0,43 \\
\text { Diode } \mathrm{C}: 0,38 \\
\text { Diode } \mathrm{D}: 0,40 \\
\text { Diode } \mathrm{E}: 0,39 \\
\text { Diode } \mathrm{F}: 0,40\end{array}$} \\
\hline \multicolumn{2}{|c|}{ Cara Pemeliharaan } \\
\hline \multicolumn{2}{|c|}{$\begin{array}{l}\text { Langkah - langkah yang dilakukan untuk mengecek dioda adalah: } \\
\text { 1) Mengecek dioda secara forward bias (bias maju). Hasilnya terukur sebesar 0,4 V DC. } \\
\text { Jika saat dioda di simulasi bias maju ada tegangan yang terukur, maka disimpulkan } \\
\text { dioda dalam keadaan normal kondisinya bagus. } \\
\text { 2) Mengecek dioda secara reverse bias (bias mundur). Hasilnya terukur open loop (OL). } \\
\text { Hal ini membuktikan bahwa saat keadaan normal dioda memblok arus yang } \\
\text { berlawanan arah dengan arus dioda. }\end{array}$} \\
\hline Setelah Dilakukan Perawatan & Analisa Setelah perawatan \\
\hline $\begin{array}{l}\text { Setelah dilakukan pengencangan lalu } \\
\text { pengukuran tegangan diode yang } \\
\text { didapat. } \\
\text { Diode A: } 0,41 \\
\text { Diode } \mathrm{B}: 0,43 \\
\text { Diode } \mathrm{C}: 0,38 \\
\text { Diode } \mathrm{D}: 0,40 \\
\text { Diode } \mathrm{E}: 0,39 \\
\text { Diode } \mathrm{F}: 0,40\end{array}$ & $\begin{array}{l}\text { Untuk perkejaan pengencangan sebaiknya memakai } \\
\text { kunci torsi agar tidak terjadi crack di sisi terminal } \\
\text { sambungan sesuai rujukan dari manufacture. } \\
\text { Selebihnya sudah sesuai standar seperti nominal kerja } \\
\text { rata rata diode yaitu } 0,4 \text { VDC [7]. }\end{array}$ \\
\hline
\end{tabular}

Tabel 9. Perawatan Ventilation System Masalah Sebelum Pemeliharaan

Kotor dibagian body motor dengan banyaknya debu. Untuk tahanan isolasi cukup baik, nilai yang didapat untuk motor tegangan 400VAC yaitu $89,7 \mathrm{M} \Omega$. sedangkan untuk motor tegangan 24VDC yaitu $1,031 \mathrm{M} \Omega$.

Cara Pemeliharaan

Measure insulation resistance both $A C$ and DC motor.

Tahanan isolasi inlet fan motor 24 VDC dan inlet damper motor 400 VAC diukur dengan menghubungkan antara tiga fasa secara bergantian yaitu fasa $\mathrm{R}-\mathrm{S}$, fasa $\mathrm{R}-\mathrm{T}$, fasa $\mathrm{S}-\mathrm{T}$. Minimum tahanan isolasi untuk motor $24 \mathrm{~V} \mathrm{DC}$ menurut standar Pertamina yaitu sebesar 1,024 $\mathrm{M} \Omega$. Sedangkan minimum tahanan isolasi untuk motor $400 \mathrm{~V}$ AC berdasarkan standar Pertamina yaitu sebesar $1,4 \mathrm{M} \Omega$.

Check bearing condition

Pemeliharaan bearing motor sama seperti pada bearing rotor. Untuk prosedur dan tata cara melepas, memasang dan pengecekan visual bearing dapat dilihat pada pemeliharaan bagian rotor sub bearing

Check electrical connection

Koneksi antara winding terminal harus kencang dan tidak boleh adanya kelonggaran dengan 
212 Abdul Zain, Wildan Alif Imam Putra. Analisa Perawatan Diesel Engine Generator(DEG) Tunu South Production Platform Pertamina Hulu Mahakam

\begin{tabular}{|c|c|}
\hline asa. & \\
\hline Setelah Dilakukan Perawatan & Analisa Setelah perawatan \\
\hline 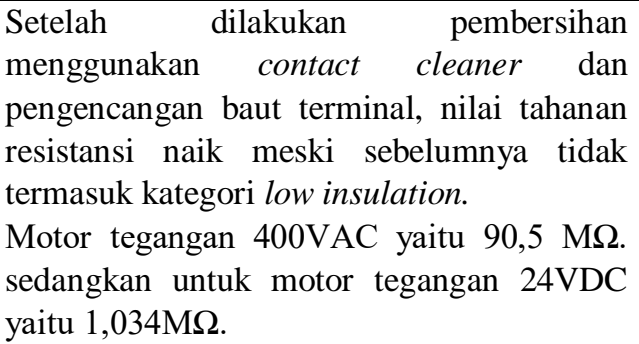 & $\begin{array}{l}\text { Metoda yang tepat dengan melakukan perawatan } \\
\text { di sisi Motor auxiliaries, karena fungsi yang } \\
\text { diberikan cukup vital untuk sirkulasi udara } \\
\text { didalam package engine generator [6]. }\end{array}$ \\
\hline
\end{tabular}

\section{KESIMPULAN}

Berdasarkan hasil dan analisa data diatas, maka dapat disimpulkan sebagai berikut:

a. Pemeliharaan DEG sebaiknya mengutamakan komponen auxiliary generator disamping komponen utamanya, karena sebagian besar penyebab unplanned shutdown merupakan kegagalan fungsi dari auxiliary generator.

b. Memastikan ketersediaan spare part DEG agar dapat melakukan action cepat (follow-up action) saat ditemukan peralatan yang sudah tidak berkerja dengan baik dan tidak sesuai system.

c. Merevisi prosedur pemeliharaan dan peralatan yang lebih update dalam rangka memperbaiki kualitas pemeliharaan DEG yang lebih ekonomis dan handal dalam jangka waktu yang lama.

\section{DAFTAR PUSTAKA}

[1] H. I. Al-Fikri, "Analisis Pembangkit Listrik Dengan Generator Stirling.” Tanjungpura University.

[2] I. Endrawijaya, "Analisis Hubungan Kinerja Genrator Set Dengan Pemeliharaan Berkala Di Banda Udara Adisucipto Yogyakarta," Langit Biru J. Ilm. Aviasi, vol. 6, no. 14, 2013.

[3] B. SAPUTRO, "Analisis Keandalan Generator Set sebagai Power Supply Darurat Apabila Power Supply dari PLN Mendadak Padam Di Morodadi Poultry Shop Blitar," J. Qua Tek., vol. 7, no. 2, pp. 17-25, 2017.

[4] M. A. Suyuti and R. Nur, "Determining Interval Time of Maintenance in Bosowa Cement Indonesia using Reliability Method," INTEK J. Penelit., 2016.

[5] D. Marsudi, "Pembangkitan energi listrik," Erlangga, Jakarta, vol. 2, 2005.

[6] T. Wireman, Training programs for maintenance organizations, vol. 5. Industrial Press Inc., 2010.

[7] J. Pyrhonen, T. Jokinen, and V. Hrabovcova, Design of rotating electrical machines. John Wiley \& Sons, 2013.

[8] J. Levitt, Complete guide to preventive and predictive maintenance. Industrial Press Inc., 2003. 